\section{A interdisciplinaridade na investigação epidemiológica: algumas lições dos trabalhos pioneiros de Frederico Simões Barbosa}

\author{
Interdisciplinarity in epidemiological research: \\ some lessons from the pioneering work of \\ Frederico Simões Barbosa
}

\author{
La interdisciplinariedad en la investigación \\ epidemiológica: algunas lecciones de los trabajos \\ pioneros de Frederico Simões Barbosa
}

Mauricio L. Barreto ${ }^{1}$

Em especial, gostaria de focar meu comentário em dois trabalhos complementares, os quais à época chamaram a minha atenção, interesse e curiosidade. O primeiro publicado em 1981, no American Journal of Epidemiology 1, e o segundo um ano após, no Memórias do Instituto Oswaldo Cruz ${ }^{2}$. Tais trabalhos exploram o impacto da esquistossomose na produtividade de trabalhadores cortadores de cana em uma usina de seu querido Pernambuco. Em primeiro lugar, esses trabalhos explicitam a vocação genuinamente interdisciplinar que se encontra presente na investigação científica de epidemiologistas pioneiros e originais, como o foi Simões Barbosa.

A esquistossomose era considerada, na época da investigação, uma das mais importantes endemias dos países subdesenvolvidos da América Latina, África e Ásia. Epidemiologistas e tropicalistas americanos e europeus estudavam com afinco as suas implicações em saúde e, associados a economistas, fizeram explorações sobre as suas implicações econômicas. Os estudos econômicos, de maneira pragmática, iriam justificar os investimentos necessários para o controle dessa e de outras endemias. Porém, a sua referência maior era enfatizar a importância das "doenças tropicais" na explicação do subdesenvolvimento ${ }^{3}$.

Os primeiros estudos sobre o impacto econômico da esquistossomose datam da década de 1960, na África 4,5. No entanto, o modelo mais bem concebido desta linha de investigação será 
realizado por um grupo de economistas americanos, na ilha caribenha de Santa Lúcia, onde se desenvolvia um programa modelo de controle da esquistossomose com financiamento da Fundação Rockfeller 6 . O estudo econômico foi publicado em 1973 em forma de livro 7 e teve o objetivo de desenvolver alternativas para medir o impacto da esquistossomose sobre a produtividade do trabalho e da performance de escolares pela comparação de grupos infectados e não infectados, mas vai muito além e explicita de maneira razoavelmente clara o quadro conceitual sobre o qual essa linha de investigação se situa.

Não há duvida de que o estudo de Santa Lúcia será inspirador para os estudos empreendidos por Barbosa e Pereira da Costa 1,2 entre os canavieiros pernambucanos. A atualidade da questão, a rigorosa abordagem metodológica e a qualidade dos artigos finais mostram a familiaridade dos autores com o tema proposto e o seu domínio da investigação epidemiológica e mesmo dos métodos econométricos usados. Utilizam-se de abordagens retrospectivas e prospectivas ao investigarem em detalhe o impacto sobre a produtividade das diversas formas clínicas da esquistossomose, em especial as formas severas, nessa população de trabalhadores submetidos a condições extremas de trabalho. Os resultados mostram reduções significativas na produtividade dos cortadores acometidos com a forma hepato-esplênica, em relação a trabalhadores com outras formas mais benignas. Nesse aspecto, os seus métodos e resultados são mais robustos e convincentes do que aqueles apresentados no trabalho que serviu de inspiração. Os autores vão além e, pela pequena amostra estudada, extrapolam os efeitos para estimar as perdas de produtividade de toda a usina e mais ainda para todas as regiões produtoras de açúcar do Brasil. As estimativas produzem figuras impressivas sobre a queda de produtividade gerada pela esquistossomose na produção nacional de cana. Contudo, este foi, sem dúvida, um dos importantes equívocos dos autores, conforme assinalado por Davidson alguns anos após a publicação dos estudos originais 8 .

Na visão de Davidson ${ }^{8}$, para fazer tal extrapolação seria necessário aceitar que na força de trabalho não existiriam substitutos ou trabalhadores suplementares que compensassem os cortadores de cana com a doença nas suas formas mais severas.
Um ponto para debate seria o porquê os autores, ao apresentarem seus impressivos resultados, não pensaram sobre essa alternativa de explicação. Essa é uma questão difícil de ser respondida, entretanto eu gostaria de refletir sobre alguns aspectos. No caso específico, é indispensável entender como essa linha de trabalho trilhada por Barbosa e Pereira da Costa 1,2 se situa com relação a dois debates importantes que os antecede 7 . Primeiro, a colocação da saúde integrando as teorias econômicas que colocam atribuem à doença um valor monetário. Segundo, a ideia de que as doenças dos países subdesenvolvidos seriam um dos importantes fatores explicativos para a estagnação econômica deles. Esta última concepção teve grande aceitação a partir da década de 1950, como parte do modelo econômico desenvolvimentista dominante na época 9. Esse modelo concebia o subdesenvolvimento como intrínseco às condições prevalentes em cada país, incluindo as suas doenças, e fornecia aos economistas desta corrente de pensamento elementos para negar o papel da exploração imperialista na manutenção do subdesenvolvimento. Na epidemiologia, essas ideias seriam mais tarde reorganizadas em torno das chamadas teorias da transição demográfica 10 e da transição epidemiológica 11 . As críticas eventuais aos trabalhos de Barbosa e Pereira da Costa 1,2 em nenhum momento diminuem a sua importância e pertinência no contexto em que foi desenvolvido. Porém, são de imensa importância para a reflexão de que, ao praticar a interdisciplinaridade, o epidemiologista deve observar que utilizar os métodos e técnicas de outras disciplinas imbrica, muitas vezes sem a consciência necessária, conceitos e teorias que estão contidos nessas disciplinas. No caso especifico das ditas doenças tropicais (hoje negligenciadas) endêmicas ou epidêmicas, os conhecimentos sobre as elas foram (e continuam sendo) manipuladas pelos países centrais para justificar o seu entendimento e suas formas de conexão com o problema do colonialismo, subdesenvolvimento e pobreza na maior parte do planeta. Ao não considerar esses aspectos, os estudos sobre tais doenças ficam limitados ao contexto em que são produzidas, perdendo-se a possibilidade de integrá-los a uma perspectiva mais abrangente de entender as doenças como parte de trajetórias históricas que extrapolam os contextos específicos em que ocorrem 12. 
1. Barbosa FS, Pereira da Costa DP. Incapacitating effects of schistosomiasis mansoni on the produc tivity of sugar-cane cutters in northeastern Brazil. Am J Epidemiol 1981; 114:102-11.

2. Pereira da Costa DP, Simões Barbosa F. Efeito da esquistossomose na produtividade do cortador de cana ao longo da safra de açúcar da Usina Catende, Pernambuco. Mem Inst Oswaldo Cruz 1982; 77:425-9.

3. Bleakley H. Health, human capital, and development. Annu Rev Econom 2010; 2:283-310.

4. Fenwick A, Figenschou BH. The effect of Schistosoma mansoni infection of the productivity of cane cutters on a sugar estate in Tanzania. Bull World Health Organ 1972; 47:567-72.

5. Collins KJ, Brotherhood RJ, Davies CT, Doré C, Hackett AJ, Imms FJ, et al. Physiological performance and work capacity of Sudanese cane cutters with Schistosoma mansoni infection. Am J Trop Med Hyg 1976; 25:410-21.

6. Jordan P. Schistosomiasis. The St Lucia Project. Cambridge: Cambridge University Press; 1983.
7. Weisbrod BA, Andreano RL, Baldwin RE, Epstein EH, Kelley AC, Helminiak TW. Disease and economic development: the impact of parasitic diseases in St Lucia. Madison: University of Wisconsin Press; 1973.

8. Davidson RK. Re: "Incapacitating effects of Schistosomiasis mansoni on the productivity of sugarcane cutters in northeastern Brazil". Am J Epidemiol 1985; 121:476.

9. Rostow WW. The stages of economic growth: a non-communist manifesto. New York: Cambridge University Press; 1991.

10. Frederiksen H. Feedbacks in economic and demographic transition. Science 1969; 166:837-47.

11. Omran AR. The epidemiologic transition: a theory of the epidemiology of population change. Milbank Mem Fund Q 1971; 49:509-83.

12. Watts S. Epidemics and history: disease, power and imperialism. New Haven: Yale University Press; 1995. 